\title{
The mental state examination
}

\section{Sarah Huline-Dickens}

\begin{abstract}
SUMMARY
The mental state examination is unlike any other assessment in medicine. Karl Jaspers is largely attributed with describing the structure and method of its use. In the centenary year of Jaspers' seminal work General Psychopathology, psychiatry can celebrate the mental state examination as part of its rational and secular heritage.
\end{abstract}

\section{DECLARATION OF INTEREST}

None.

'How in the world is it possible to say what relieves a madman of responsibility until you know what makes a sane man responsible?'

\section{Henry Maudsley}

The mental state examination is unlike any other assessment in medicine in drawing so directly on a humanistic and scientific approach to understanding the patient. To the trainee it must appear mysterious that standard textbooks fail to acknowledge its origin. There is little literature on the evidence behind using it, nor is there much educational research on how it should be taught. Even a contemporary book dedicated solely to it makes no mention of where it comes from (Trzepacz 1993). Yet it has attained the unusual status of a precisely defined learning objective within Tomorrow's Doctors, where it is specified that doctors on qualifying must be able to perform a mental state examination and interpret the findings (General Medical Council 2009).

Its origin is, as psychiatric practice itself, complex. Several excellent histories of psychiatry and the study of psychopathology exist (e.g. Bynum 1983) and attest to the emergence of societal interest in disruptive behaviour and developing notions of social and criminal responsibility in the 15 th and 16th centuries. It was of importance, for example, to have some means of assessing an individual's internal world when needing to establish a person's beliefs in a religious context, such as during the Spanish Inquisition.

Early descriptions of psychiatric assessment (see, for example, Bucknill 1856) lay great stress on information from relatives, a change in habits and on careful observation of the insane in their natural environment. There was also a focus on appearance, behaviour, gestures and abnormal movements as part of an assessment. But at this time only five categories of insanity were recognised: mania, monomania, melancholia, dementia and idiocy, and presumably assessments were largely employed to differentiate between these and to decide on which setting would be most appropriate for care.

\section{The modern description}

It was Karl Jaspers who saw that examination of the individual case by biographical method was the basic source for all that counts as experience in psychopathology. Indeed, the case study remains a fundamental method of investigating psychopathology today. Barely 30, Jaspers wrote General Psychopathology in 1913, yet it was not translated into English until 1963, despite being already in its seventh edition (Trethowan 1988). In his preface to the first edition, Jaspers wished to stress that the task was not to learn the material, but rather 'to learn to observe, ask questions, analyse and think in psychopathological terms.' This was not a time of therapeutic optimism, and Jaspers recognised that although scientific principles and the knowledge of brain disease were important bases of knowledge, the social sciences were also relevant disciplines for the psychiatrist. His suggestions of how a patient might be examined can be found in the appendix of this work and he lays out the principles of his method in the introduction (Jaspers 1913).

Jaspers stressed the need for theory, recognised but did not aim to study the unconscious, and sought what he called a psychology of meaningful connections. He tried to delineate subjective from objective phenomena, acknowledging that the distinction was often problematic. In his 'enquiry into connections', arguably one of the more difficult aspects of the work to apprehend and one that has excited much critical writing, he distinguished between the term verstehen, the understanding of meaning from within, and erklaren, the explanation of causal connections from without. Fulford et al (2006), who discuss Jaspers and his philosophical legacy at length, derive an additional organising principle - that of form and content for the purpose of their analysis.

Jaspers also thought it essential to grasp the complex unity of the whole phenomenon under
Sarah Huline-Dickens is a consultant child and adolescent psychiatrist in Plymouth and an academic clinical senior lecturer at Peninsula College of Medicine and Dentistry, UK.

Correspondence Dr Sarah Huline-Dickens, Erme House, Mount Gould Hospital, Mount Gould Road, Plymouth PL4 70D, UK. Email: sarah. huline-dickens@pms.ac.uk 
a. Descriptive psychopathology, as used by Sims (1988), refers to the description and categorisation of abnormal experience as recounted by the patient and observed in their behaviour. study, and he had plenty to say about how research should be done. He had a strong aversion to 'fanaticism', a desire for clarity and advised against 'the slide into endlessness' where facts and thinking might be correct but bring no new knowledge. He thought that psychiatrists should have knowledge about the humanities and social sciences, and also expected certain standards from publications on psychopathology, stipulating that they should avoid arguing until doomsday.

\section{The contemporary description}

The British interest in descriptive psychopathology $\mathrm{y}^{\mathrm{a}}$ - for this is the term used to describe what the mental state examination aims to elicit - was late to arrive, but became decisively incorporated into the Royal College of Psychiatrists' training and examinations structure. The first edition of Symptoms in the Mind (Sims 1988) provided some guidance, albeit somewhat daunting, for the trainee:

'Eliciting the symptoms involves observing the whole repertoire of behaviour and listening to an extensive description of the internal state and then reducing this to a few summarizing sentences.'

How this was done was by use of the right words, trained observation, using one's own capacity for emotion as a diagnostic tool, the importance of knowing why you were asking the question you asked, and by knowing when to pursue more detailed lines of enquiry.

Attempts to operationalise assessment of the mental state using checklists and rating scales have ultimately led to international collaborations and to the development of research diagnostic criteria for mental disorders. One of the first of these was a version by Spitzer et al (1964), and several modifications have been made since then, including the Present State Examination (PSE) by Wing et al (1967). The mental state examination is therefore an examination of extraordinary global and political significance.

Even as a mere checklist, and with no mention of the empathic method of applying it, the mental state examination has been described as fundamental to the assessment of capacity in a legal sense. So, for example, the British Medical Association in collaboration with the Law Society have written guidance for doctors and lawyers on just this subject (British Medical Association 2004) using the headings of that well-known formula (Box 1).

Much remains to be debated by medical historians and psychiatrists about the relationship between other phenomenologists and Jaspers and
BOX 1 Mental state examination structure

\begin{tabular}{ll}
\hline - Appearance and & - Perception \\
behaviour & - Cognition (orientation, \\
- Speech & memory and intelligence) \\
- Mood & Insight \\
- Thought & (British Medical Association \\
&
\end{tabular}

what kinds of mental state assessments were being used in Britain before Jaspers' book was widely available. But this is an examination that is core to our specialty. It is a critical part of our method of clinical reasoning, encapsulated by Goldney $\&$ McFarlane (1986) as the ability to observe psychopathology, to engage in interpersonal interaction to elicit information and to apply academic knowledge to help solve a clinical problem.

The mental state examination, within the context of the psychiatric assessment, is a unique way of attempting to understand individual psychopathology and the patient's perspective on this. So, as we approach the anniversary of Jaspers' seminal work in 2013, psychiatrists can celebrate the mental state examination, and renewed attention to Jaspers' insistence on the need to understand complex mental experience will resonate with both clinicians and patients.

\section{References}

British Medical Association (2004) Assessment of Mental Capacity: Guidance for Doctors and Lawyers. BMJ Books.

Bucknill JC (1856) The diagnosis of insanity. British Journal of Psychiatry 2: 229-45.

Bynum WF (1983) Psychiatry in its historical context. In Handbook of Psychiatry Volume 1: General Psychopathology (ed M Shepherd): 11-38. Cambridge University Press.

Fulford KWM, Thornton T, Graham G (2006) Oxford Textbook of Philosophy and Psychiatry. Oxford University Press.

General Medical Council (2009) Tomorrow's Doctors. GMC.

Goldney RD, McFarlane AC (1986) Assessment in undergraduate psychiatric education. Medical Education 20: 117-22.

Jaspers K (1913) (1963 trans by J Hoenig \& M Hamilton, 1997 reprint) General Psychopathology. Johns Hopkins University Press.

Sims A (1988) Symptoms in the Mind: An Introduction to Descriptive Psychopathology. Baillière Tindall.

Spitzer R, Fleiss J, Burdock E, et al (1964) The mental status schedule: rationale, reliability, and validity. Comprehensive Psychiatry 5: 384-95.

Trethowan W (1988) Foreword. In Symptoms in the Mind: An Introduction to Descriptive Psychopathology (ed A Sims). Baillière Tindall.

Trzepacz PT, Baker RW (1993) The Psychiatric Mental Status Examination. Oxford University Press.

Wing JK, Birley JLT, Cooper JE, et al (1967) Reliability of a procedure for measuring and classifying 'present psychiatric state'. British Journal of Psychiatry 113: 499-515. 